\title{
Dentists' knowledge about osteoporosis and their ability to identify the disease
}

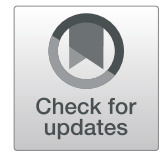

Renato Vicente Ferreira ${ }^{1}$, Suely Roizenblatt ${ }^{2 *}$ (D) and Vera Lucia Szejnfeld ${ }^{2}$

\begin{abstract}
Background: Osteoporosis is an underdiagnosed condition, and its seriousness is not considered until severe complications arise. This study aimed to evaluate general dentists' knowledge about osteoporosis and their ability to identify patients with this disease by assessing mandibular cortical width (MCW) and mandibular cortical index (MCI) on panoramic dental radiographs using a visual method.

Methods: In this cross-sectional study, an email questionnaire regarding the diagnosis and prevention of osteoporosis was sent to 20,773 dentists in 2016. Those who completed the questionnaire were invited to participate in radiomorphometric training and then to analyze the $\mathrm{MCl}$ and $\mathrm{MCW}$ of 114 panoramic radiographs of postmenopausal women who underwent both panoramic radiography and bone densitometry. Based on the radiomorphometric indices and while blinded to the densitometry results, the dentists determined whether they would indicate densitometry for these patients.

Results: The response rate was 2.3\%: 485 dentists completed the questionnaire, and 50 evaluated panoramic radiographs using the $\mathrm{MCW}$ and $\mathrm{MCl}$. All of them reported some knowledge about osteoporosis, but $41.6 \%$ demonstrated a misleading conceptualization of the disease. Approximately $90 \%$ reported minimal access to this information during graduation, and only $27.0 \%$ were exposed to the topic during their postgraduate studies. Interest in osteoporosis prevention was expressed by $70.7 \%$ of the respondents, and interest in learning the radiomorphometric indices was expressed by $99.0 \%$. The sensitivity in the detection of low bone mineral density through the MCW and MCI was $52.9 \%$, and the specificity was $64 \%$.
\end{abstract}

Conclusions: Brazilian dentists demonstrated insufficient knowledge about osteoporosis and a low ability to detect osteopenia or osteoporosis by applying radiomorphometric indices.

Keywords: Osteoporosis, Radiography, Dental education, Educational methods

\section{Background}

Osteoporosis is characterized by microstructural deterioration and loss of bone mass, leading to decreased bone strength and quality and an increased risk of fragility fractures. Osteoporosis is typically an underdiagnosed condition, and the identification of affected individuals before the condition is established and a fracture occurs is a major challenge.

\footnotetext{
* Correspondence: suely.roizenblatt@unifesp.br

${ }^{2}$ Department of Internal Medicine, Universidade Federal de Sao Paulo (UNIFESP), Rua Angelina Maffei Vita 670, Sao Paulo, SP CEP:01455070, Brazil Full list of author information is available at the end of the article
}

Dual-energy X-ray absorptiometry (DXA) scans are currently considered the standard diagnostic approach for osteoporosis, and peripheral imaging techniques, such as peripheral quantitative tomography, peripheral DXA, quantitative ultrasound methods, and peripheral magnetic resonance imaging, have been used as screening tests to identify individuals who are most likely to benefit from further bone density testing. In this context, an increasing number of studies have proposed the use of quantitative/qualitative indices on dental panoramic radiographs to identify low bone mass $[1,2]$. Assessment of the trabecular pattern of the mandible using panoramic radiographs has been considered a valid tool for

(c) The Author(s). 2021 Open Access This article is licensed under a Creative Commons Attribution 4.0 International License, which permits use, sharing, adaptation, distribution and reproduction in any medium or format, as long as you give appropriate credit to the original author(s) and the source, provide a link to the Creative Commons licence, and indicate if changes were made. The images or other third party material in this article are included in the article's Creative Commons licence, unless indicated otherwise in a credit line to the material. If material is not included in the article's Creative Commons licence and your intended use is not permitted by statutory regulation or exceeds the permitted use, you will need to obtain permission directly from the copyright holder. To view a copy of this licence, visit http://creativecommons.org/licenses/by/4.0/. 
identifying individuals with osteoporosis, as a substantial number of patients are subjected to dental radiographs each year for diagnostic and treatment purposes [3]. Therefore, it would be of great clinical benefit if dentists could identify patients at a high risk for osteoporosis using these radiographs. In the academic environment, radiomorphometric indices applied to panoramic radiographs have been used to estimate osteopenia and osteoporosis based on established cutoff values [4].

As shown in the large European multicenter study OSTEODENT $[5,6]$, much interest was expressed on the cortical bone layer at the lower border of the mandible. In this study involving five European centers between 2003 and 2005, mandibular cortical width (MCW) was considered an alternative method for assessing bone changes related to osteoporosis in panoramic X-rays of patients who had undergone radiographic evaluation for the usual dental reasons, not as a formal risk assessment tool $[5,6]$.

Strategies have been implemented to encourage dentists' involvement in general health promotion activities, particularly for diabetes and cardiovascular diseases [7, 8]. Regarding osteoporosis, few studies have addressed dentists' knowledge, and most of these studies are related to mandibular osteonecrosis and its association with bisphosphonates $[9,10]$.

In this study, we aimed to investigate dentists' knowledge about the prevention and diagnosis of osteoporosis and to verify their ability to detect this disease by applying a simple visual method for evaluating radiomorphometric cortical indices on panoramic dental radiographs.

\section{Methods}

\section{Participants}

This cross-sectional study included general dentists with $\geq 2$ years of registration at the Regional Dentistry Council of the State of São Paulo (CROSP). After approval by its internal scientific council, CROSP released an e-mail message to 20,733 actively practicing dentists requesting information about their general profile (age, gender, years since graduation), excluding those specialized in dental radiography. The participants were then directed to a structured questionnaire regarding osteoporosis.

The dentists who answered the questionnaire were invited to evaluate the panoramic dental radiographs of 114 postmenopausal female patients, consecutively selected from the Osteoporosis Ambulatory of the Outpatient Clinic for Osteometabolic Diseases in the Rheumatology Division of Federal University of São Paulo (UNIFESP) between January 2016 and January 2017. These women (age range $50-78$ years) were concomitantly imaged with panoramic radiographs and DXA of the spine and femur. There were 38 women in each of the following conditions: normal DXA, osteopenia and osteoporosis.
The study was approved by the Ethics Committee of UNIFESP - CEP \# 2.193.407. After providing written informed consent, patients underwent mandibular panoramic radiography and DXA of the spine and femur. Electronic signed consent was obtained from the dentists who agreed to participate in this research.

\section{Questionnaire}

To evaluate the knowledge about osteoporosis, we used a structured questionnaire [11] previously applied to Brazilian physicians [12]. From a total of 27 questions, 14 items related to medical specialties, such as treatment, were removed, and five other items were added: three about previous osteoporosis knowledge selected from the BRAZOS questionnaire [13] and two regarding the methods used to evaluate osteoporosis on panoramic dental radiographs. Thus, the final questionnaire had a total of 18 questions.

\section{Distribution and collection of the questionnaire}

For the approach through e-mail, CROSP requested voluntary participation by dentists through a message that included a link to the online Survio ${ }^{\text {mo }}$ survey platform (SurveyGizmo, Boulder, CO). The participant was then directed to an online interface displaying the research questionnaire. The e-mail message was sent only once to each CROSP member, and the platform remained open for 6 months. The interested members could access the platform only once during this period. No advantages or remuneration was offered to the participants.

\section{Acquisition and evaluation of panoramic radiographs}

The panoramic radiographs were obtained with an Eagle 2D panoramic OP 3000 2D (Dabi Atlante, Ribeirão Preto, Brazil) by the same experienced operator, with the patient in a standardized position predefined by the equipment.

The modified visual method for evaluating cortical indices, such as the MCW and the mandibular cortical index (MCI), was used in this research [14] by 50 dentists who agreed to be trained on both indices through e-learning classes using Klickmembers ${ }^{\mathrm{Tw}}$ (Klickpages information technology and services, DF, Brazil). This platform includes video classes and secure-access exercises. For training purposes, restrictive access for each dentist was provided by means of an individual password for a period of 7 to 10 days. After completing all classes and clarifying any lingering doubts, those 50 dentists were invited to assess the panoramic radiographs in this study and to answer the following question: "Would you recommend DXA to this patient?" The possible answers were "yes", "no", and "I do not know". 
In a small room provided with individual X-ray illuminators, there was a box containing the panoramic radiographs of the 114 postmenopausal women. The dentists were asked to randomly select 10 radiographs per turn for visual evaluation of the MCW and MCI while blinded to the DXA results, and then to return the radiographs to the box. Finally, we obtained 1170 views, with an average of 26 views per dentist.

\section{Statistical analysis}

The results are expressed as frequencies and percentages. Correlations between radiomorphometric indices and bone density were analyzed using the Spearman correlation coefficient test. The kappa coefficient was used to assess the agreement between the dentists' opinions based on the panoramic radiographs and the DXA results. We used SPSS software version 22.0 (Chicago, IL, USA), and the significance level was $5 \%$.

\section{Results}

The response rate of the 20,733 contacted dentists was 2.3\%: 485 of them answered the questionnaire, and 50 agreed to evaluate the 114 panoramic dental examinations of postmenopausal female patients. Figure 1 shows a flow chart detailing the response outcomes for the delivered questionnaires. Among the 20,733 dentists invited, 15,840 were nonresponders, 4893 (23.9\%) opened their e-mails, $902(4.3 \%)$ accessed the platform, and only 485 (2.3\%) answered the full questionnaire.

The demographic characteristics of the dentists are shown in Table 1 . The majority of the responders $(82.1 \%)$ had $>15$ years of dentistry practice experience. The frequencies of the responses to osteoporosis questions by the general dentists are presented in Table 2 . Although $41.6 \%$ of the dentists had a misleading concept of osteoporosis, most of them knew that bone densitometry was used to diagnose osteoporosis and identified the commonly affected age groups. In addition, 58.6\% were not aware of which dentistry methods were available for the diagnosis of osteoporosis. Nevertheless, 99\% demonstrated interest in learning these techniques. The dentists' responses to information about osteoporosis obtained during graduation and postgraduate courses are presented in Table 3. Most dentists had little or no exposure to this topic, but $58.8 \%$ of them rated the access to information about osteoporosis as "easy".

The 50 previously trained dentists randomly and blindly analyzed these radiographs, completing 1170 views. The correlation of bone mineral density status and the radiomorphometric indices was 0.326 for $\mathrm{MCI}$ and 0.283 for MCW $(p<0.01)$. The agreement between the dentists' opinions and the densitometry results is presented in Table 4. The dentists' evaluations had a sensitivity of $52.9 \%$ and a specificity of $64.0 \%$.

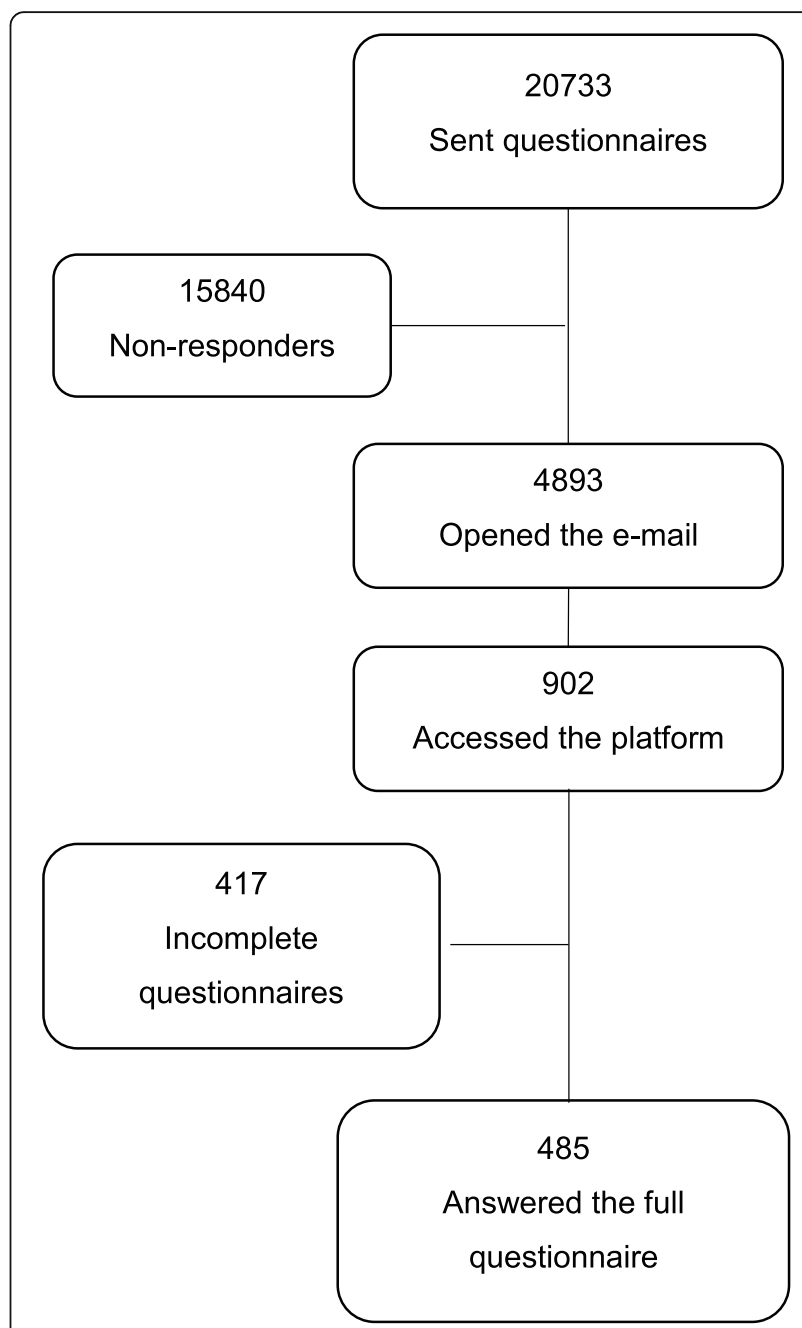

Fig. 1 Response outcomes to the mailed questionnaire

\section{Discussion}

This study showed a low return rate for the questionnaire and, among the responders, superficial knowledge about osteoporosis and a low ability to evaluate cortical indices on panoramic dental radiographs.

Only $4.0 \%$ of the 20,733 dentists accessed the platform, and $2.3 \%$ completed the questionnaire. This low return

Table 1 Demographic characteristics of the dentists

\begin{tabular}{lll}
\hline & Number & $\%$ \\
\hline Gender & & \\
Male & 201 & $41.1 \%$ \\
Female & 284 & $58.6 \%$ \\
Years since graduation & & \\
$0-5$ & 17 & $3.5 \%$ \\
$5-10$ & 24 & $4.9 \%$ \\
$10-15$ & 46 & $9.5 \%$ \\
$>15$ & 398 & $82.1 \%$ \\
\hline
\end{tabular}


Table 2 frequencies of response to osteoporosis questions by general dentists

\begin{tabular}{|c|c|c|}
\hline Question & Answer & Frequency \\
\hline \multirow[t]{2}{*}{ Have you heard about osteoporosis? } & Yes & $485(100 \%)$ \\
\hline & No & $0(0.0 \%)$ \\
\hline \multirow[t]{3}{*}{ Which of these phrases best define osteoporosis? } & Stronger bones, rich in calcium & $0(0 \%)$ \\
\hline & Fragile bones that break easily & $283(58.4 \%)$ \\
\hline & Lack of calcium in the bones & $202(41.6 \%)$ \\
\hline \multirow[t]{7}{*}{ From the tests below, which is the main one to diagnose osteoporosis? } & Outpatient visit & $3(0.6 \%)$ \\
\hline & X-ray & $3(0.6 \%)$ \\
\hline & Computed tomography & $3(0.6 \%)$ \\
\hline & Urine analysis & $0(0.0 \%)$ \\
\hline & Blood test & $8(1.6 \%)$ \\
\hline & Bone densitometry & $466(96.1 \%)$ \\
\hline & Magnetic resonance imaging & $2(0.4 \%)$ \\
\hline \multirow[t]{6}{*}{ Which are the appropriate age group(s) to start screening for osteoporosis? } & Childhood ( $0-8$ years) & $0(0 \%)$ \\
\hline & Preteen (8-12 years) & $1(0.2 \%)$ \\
\hline & Teen (12-19 years) & $0(0.0 \%)$ \\
\hline & Early adulthood (19-40 years) & $1(0.2 \%)$ \\
\hline & Mid-life (40-66 years) & $230(47.4 \%)$ \\
\hline & Elderly (> 66 years) & $253(52.2 \%)$ \\
\hline \multirow{2}{*}{$\begin{array}{l}\text { Do you know any method in dentistry that can indicate the presence of osteoporosis } \\
\text { in the patient? }\end{array}$} & Yes & $201(41.4 \%)$ \\
\hline & No & $284(58.6 \%)$ \\
\hline \multirow{2}{*}{$\begin{array}{l}\text { Would you like to know a method to identify osteoporosis using panoramic maxilla } \\
\text { and mandible X-rays? }\end{array}$} & Yes & $480(99.0 \%)$ \\
\hline & No & $5(1.0 \%)$ \\
\hline \multirow[t]{2}{*}{ Are you interested in advising your patients on this disease preventively? } & Yes & $480(99.0 \%)$ \\
\hline & No & $5(1.0 \%)$ \\
\hline
\end{tabular}

rate is in accordance with a previous survey carried out by our group [12], in which we administered a similar questionnaire to 11,000 Brazilian general practitioners (GPs) and achieved a response rate of $3 \%$. International surveys have achieved higher return rates than these Brazilian surveys. In a study involving GPs from the United Kingdom, 1153 out of the 2515 sent questionnaires were answered, resulting in a response rate of 46\% [11]. A Canadian survey achieved a response rate of $30 \%$ by using an online questionnaire focused on a dentistry theme of interest: osteonecrosis of the jaw [15].

A systematic review compared the performance on electronic questionnaires and face-to-face interviews among health professionals and demonstrated a variable response rate, with better results for the presential ones. The return rates of the questionnaires sent via e-mail were between 0.3 and $70 \%$ [16]. There was no difference in the quality of the results obtained by electronic survey with those obtained with other methods. In contrast, another systematic review reported that surveys with electronic questionnaires had a lower return rate than those conducted by other routes [17] and that there is great variation between the methods used for online and in- person surveys, impeding a clear idea about this topic. The authors suggested that monetary incentives did not influence the return rate of the questionnaires. Therefore, the low return rate of our questionnaire cannot be attributed to its straightforward design that lacked any incentives or rewards. We assume, unfortunately, that there is a lack of interest among our dentists in osteoporosis and its consequences, as we previously observed in the study with Brazilian GPs, who also demonstrated low interest in this subject [12].

Surveys on topics closer to dentistry clinical practice typically have a higher return rate than those regarding osteoporosis. Research involving dental trauma achieved a return rate of $9.6 \%$ [18], while that involving pins in endodontically treated teeth achieved a return rate of $68 \%$ [19], and that involving toward composite resins achieved a return rate of $68 \%$ [20].

The responses obtained in our study indicate that dentists, even with many years of dentistry practice experience ( $>15$ years), have superficial knowledge about osteoporosis, with $41.6 \%$ considering that the best phrase to define osteoporosis was a "lack of calcium in bones". This is a popular but incorrect concept since in 
Table 3 Frequencies of responses to questions about exposure to information on osteoporosis

\begin{tabular}{|c|c|c|}
\hline Question & Answer & Number (\%) \\
\hline \multirow[t]{4}{*}{ How would you rate your knowledge about osteoporosis acquired in dentistry school? } & None & $238(49.1 \%)$ \\
\hline & Minimal & $204(42.1 \%)$ \\
\hline & Excessive & $0(0.0 \%)$ \\
\hline & Sufficient & $43(8.9 \%)$ \\
\hline \multirow[t]{4}{*}{ How would you rate your knowledge about osteoporosis acquired during postgraduate training? } & None & $167(58.4 \%)$ \\
\hline & Minimal & $188(38.8 \%)$ \\
\hline & Excessive & $12(2.5 \%)$ \\
\hline & Sufficient & $118(24.3 \%)$ \\
\hline \multirow[t]{4}{*}{ How would you rate the access to information about osteoporosis? } & Very difficult & $9(1.9 \%)$ \\
\hline & Difficult & $144(29.7 \%)$ \\
\hline & Very easy & $47(9.7 \%)$ \\
\hline & Easy & $285(58.8 \%)$ \\
\hline \multirow[t]{4}{*}{ What type of information regarding osteoporosis are you interested in? } & Prevention & $343(70.7 \%)$ \\
\hline & Treatment & $64(13.2 \%)$ \\
\hline & Services & $18(3.7 \%)$ \\
\hline & Research & $60(12.4 \%)$ \\
\hline
\end{tabular}

osteoporosis, there is microstructural deterioration and loss of bone mass. Exposure to the topic in the graduate coursework was practically nil. When asked about the possibility of using tools for diagnosing osteoporosis on panoramic radiographs, most $(99.0 \%)$ were interested; however, $58.6 \%$ had no knowledge about these techniques. Although it is very important to target middleaged and postmenopausal women for osteoporosis screening and prevention programs, $52.2 \%$ of dentists considered the elderly age group to be most appropriate to screen for osteoporosis.

There are few studies in the literature on the specific knowledge of dentists about osteoporosis. A recent qualitative study based on focus group discussions analyzed the knowledge and attitudes of 17 Swedish dentists toward patients with osteoporosis [21]. Dentists from both public and private practice expressed insufficient knowledge of what osteoporosis is, how it is diagnosed and treated, and its consequences. Knowledge on the topic was lacking and almost entirely limited to academia. Interestingly, dentists were more familiar with

Table 4 Agreement between the dentist's opinion and the DXA results regarding osteoporosis

\begin{tabular}{lllll}
\hline DXA & \multicolumn{2}{l}{ Dentist's opinion } & Total \\
\cline { 2 - 4 } & Yes & No & Do not know & \\
\hline Yes & 421 & 299 & 75 & 795 \\
No & 100 & 240 & 35 & 375 \\
Total & 521 & 539 & 110 & 1170 \\
\hline
\end{tabular}

Kappa (S.E.) $=0.209(0.023), p<0,001$

Agreement (\%): for "Yes" $=52.9 \%$ (sensitivity) and for "No" $=64.0 \%$ (specificity) DXA dual-energy X-ray absorptiometry osteoporosis studies involving osteonecrosis of the jaw, periodontitis, and absence of teeth than with those involving osteoporosis itself [15].

There is a tendency to encourage dentists to refer patients for DXA based on the changes noted in panoramic radiographs [22]. The OSTEODENT multicenter study aimed to identify the most valid and effective radiographic index or the combination of radiography and the Osteoporosis Index of Risk (OSIRIS) applicable for dentists to diagnose osteoporosis. Although the MCW demonstrated better efficacy than the MCI in the detection of osteoporosis, the OSIRIS showed higher diagnostic validity than radiographic measurements [6]. This indicates that measurement of the MCW should be viewed as an alternative possibility for risk assessment among patients who have undergone radiography for usual dental reasons [6]. The same group from Manchester reported a good correlation between the radiomorphometric indices $\mathrm{MCW}$ and $\mathrm{MCI}$ obtained manually on panoramic radiographs by well-trained observers and computerized measurements [5].

A systematic review and meta-analysis [23] noted that manual measurement of the MCW could introduce operator-related bias. Nevertheless, the costs and complexity of semi or totally computer-driven techniques of panoramic radiograph analysis are little applicable to general dental practice and to the reality of many dental care scenarios. In addition, computer software that automatically detects the mandibular cortex on panoramic radiographs and then measures its width requires fully trained evaluators and high-precision electronic instruments [5], but this level of training and digital 
instruments are not part of routine dental practice. Artificial intelligence might be a new perspective in the diagnosis of osteoporosis, making this easier and perhaps affordable in the future [24, 25].

Currently, there is a tendency to apply simplified visual methods for MCI and MCW analysis to identify patients with osteoporosis $[4,14]$. In our study, 50 general dentists measured the MCW and MCI indices on a negatoscope by using the simplified method [14], mimicking usual clinical practice. Under these conditions, we obtained a sensitivity of $52.9 \%$ and a specificity of $64.0 \%$ between the dentists' opinions and the DXA results regarding osteoporosis. Depending on the author, the sensitivity of a dentist's evaluation of osteoporosis varies between 67 and $87 \%$, and the specificity varies between 70 and $86 \%$ [23]. Compared with our results, the higher agreement obtained in studies conducted in the academic environment shows that, aside from being simple, the radiomorphometric analysis on panoramic radiographs requires a certain degree of expertise and experience to obtain consistency in the results. These competences cannot be acquired by a general dentist when evaluating routine panoramic radiographs after an online training course. Considering that dentists have an opportunity to make unique contributions by early identifying osteoporotic patients based on their oral and dental health problems, such as reduced jawbone density, destruction of periodontal tissue, tooth loss, and temporomandibular disorders, their acquisition of fundamental skills in osteoporosis assessment during their regular course of study is imperative. The same lack of familiarity with osteoporosis has also been observed among GPs in previous studies, and the results provide important information to guide new actions targeted to these physicians $[11,12]$.

The present study has some limitations. First, the majority of the panoramic radiographs belonged to patients being treated with bisphosphonates, which can result in changes to the mandibular cortical structure, thereby introducing bias [26, 27]. Second, the performance of the dentists might have be influenced by the effectiveness of the training method; and third, the radiographs were obtained by the same operator, which does not reflect daily practice. This research intended to motivate dentists to refer patients to medical evaluation and not to make the diagnosis of osteoporosis and is in line with the necessity to increase the interest of these professionals in health-related topics not restricted to dental specialties.

\section{Conclusions}

We observed that dentists in São Paulo city have insufficient knowledge about osteoporosis and that their performance in detecting patients with osteopenia and osteoporosis by using a simple visual method to evaluate the MCW and MCI on panoramic radiographs was lower than that described in the literature. As these indices are correlated with bone mineral density and can represent an appropriate instrument for decision making, greater educational efforts must be made to promote knowledge about osteoporosis among dentists. This perspective may motivate dentists to actively participate in the fight against and prevention of this silent and devastating disease.

\section{Abbreviations}

MCW: Mandibular cortical width; MCI: Mandibular cortical index; DXA: Dualenergy X-ray scans; GP: General practitioners; OSIRIS: Osteoporosis Index of Risk

\section{Acknowledgments}

We would like to express our gratitude to the dentists who participated in this study.

\section{Authors' contributions}

RVF contributed to conception, design, data analysis, and interpretation, drafted and critically revised the manuscript. SR contributed to conception, design, data acquisition, analysis, and interpretation, drafted and critically revised the manuscript; VLS contributed to conception and data acquisition, critically revised the manuscript. All authors gave final approval and agreed to be accountable for all aspects of the work.

\section{Funding}

Not applicable.

Availability of data and materials

The datasets used in this study are available from the corresponding author on reasonable request.

\section{Declarations}

Ethics approval and consent to participate

The Institutional Research Ethics Committee approved the study, under registration number 2.193.407.

\section{Consent for publication}

Dentists and patients read and signed informed consent forms at study enrollment.

\section{Competing interests}

The authors declare that they have no competing interests or other interests that might be perceived to influence the interpretation of the article.

\section{Author details}

${ }^{1}$ Rheumatology Division, Universidade Federal de Sao Paulo (UNIFESP), Sao Paulo, Brazil. ${ }^{2}$ Department of Internal Medicine, Universidade Federal de Sao Paulo (UNIFESP), Rua Angelina Maffei Vita 670, Sao Paulo, SP CEP:01455070, Brazil.

Received: 16 October 2020 Accepted: 12 July 2021

Published online: 09 August 2021

\section{References}

1. Kanis JA, Glüer CC. An update on the diagnosis and assessment of osteoporosis with densitometry. Committee of Scientific Advisors, international Osteoporosis Foundation. Osteoporos Int. 2000;11(3):192-202. https://doi.org/10.1007/s001980050281.

2. López-López J, Estrugo-Devesa A, Jane-Salas E, et al. Early diagnosis of osteoporosis by means of orthopantomograms and oral X-rays: a systematic review. Med Oral Patol Oral Cir Bucal. 2011;16:e905-13. https://doi.org/1 0.4317/medoral.17304. 
3. Tugnait A, Clerehugh V, Hirschmann PN. Radiographic equipment and techniques used in general dental practice: a survey of general dental practitioners in England and Wales. J Dent. 2003;31(3):197-203. https://doi. org/10.1016/S0300-5712(03)00013-7

4. Lee K, Taguchi A, Ishii K, Suei Y, Fujita M, Nakamoto T, et al. Visual assessment of the mandibular cortex on panoramic radiographs to identify postmenopausal women with low bone mineral densities. Oral Surg Oral Med Oral Pathol Oral Radiol Endod. 2005;100(2):226-31. https://doi.org/10.1 016/j.tripleo.2004.11.052.

5. Devlin H, Allen PD, Graham J, Jacobs R, Karayianni K, Lindh C, et al. Automated osteoporosis risk assessment by dentists: a new pathway to diagnosis. Bone. 2007;40(4):835-42. https://doi.org/10.1016/j.bone.2006.10. 024.

6. Karayianni K, Horner K, Mitsea A, Berkas L, Mastoris M, Jacobs R, et al. Accuracy in osteoporosis diagnosis of a combination of mandibular cortical width measurement on dental panoramic radiographs and a clinical risk index (OSIRIS): the OSTEODENT project. Bone. 2007:40(1):223-9. https://doi. org/10.1016/j.bone.2006.07.025

7. Liccardo D, Cannavo A, Spagnuolo G, Ferrara N, Cittadini A, Rengo C, et al. Periodontal disease: a risk factor for diabetes and cardiovascular disease. Int J Mol Sci. 2019;20(6):1414. https://doi.org/10.3390/ijms20061414.

8. Voinescu I, Petre A, Burlibasa M, et al. Evidence of Connections Between Periodontitis and Ischemic Cardiac Disease - an Updated Systematic Review. Maedica (Buchar). 2019;14:384-90

9. Khan AA, Morrison A, Hanley DA, Felsenberg D, McCauley LK, O'Ryan F, et al. Diagnosis and management of osteonecrosis of the jaw: a systematic review and international consensus. J Bone Miner Res. 2015;30(1):3-23. https://doi.org/10.1002/jbmr.2405.

10. Wan JT, Sheeley DM, Somerman MJ, Lee JS. Mitigating osteonecrosis of the jaw (ONJ) through preventive dental care and understanding of risk factors. Bone Res. 2020;8(1):14. https://doi.org/10.1038/s41413-020-0088-1.

11. Taylor JC, Sterkel B, Utley M, Shipley M, Newman S, Horton M, et al. Opinions and experiences in general practice on osteoporosis prevention, diagnosis and management. Osteoporos Int. 2001;12(10):844-8. https://doi. org/10.1007/s001980170035.

12. Szejnfeld VL, Jennings $F$, Castro CHM, et al. Conhecimento dos médicos clínicos do Brasil sobre as estratégias de prevenção e tratamento da osteoporose. Rev Bras Reumatol. 2007;47:251-7. https://doi.org/10.1590/S04 82-50042007000400003 Available from: http://www.scielo.br/scielo. php?script=sci_arttext\&pid=S0482-50042007000400003\&lng=en\&nrm=iso. ISSN 1809-4570. [cited 15 Oct 2020].

13. Pinheiro MM, Ciconelli RM, Jacques NO, et al. The burden of osteoporosis in Brazil: regional data from fractures in adult men and women - The Brazilian Osteoporosis Study (BRAZOS). Rev Bras Reumatol. 2010;50:113-20. https:// doi.org/10.1590/S0482-50042010000200002 Available from: http://www. scielo.br/scielo.php?script=sci_arttext\&pid=S0482-50042010000200002\&lng= en\&nrm=iso. ISSN 0482-5004. [cited 15 Oct 2020].

14. Leite AF, Figueiredo PTS, Guia CM, et al. Radiografia panorâmica: instrumento auxiliar no diagnóstico da osteoporose. Rev Bras Reumatol. 2008;48:226-33. https://doi.org/10.1590/S0482-50042008000400006 Available from: http://www.scielo.br/scielo.php?script=sci_arttext\&pid=S0482-50042 008000400006\&lng=en\&nrm=iso. ISSN 1809-4570. [cited 15 Oct 2020].

15. Alhussain A, Peel S, Dempster L, Clokie C, Azarpazhooh A. Knowledge, practices, and opinions of Ontario dentists when treating patients receiving bisphosphonates. J Oral Maxillofac Surg. 2015;73(6):1095-105. https://doi. org/10.1016/j.joms.2014.12.040.

16. Marcano Belisario JS, Jamsek J, Huckvale K, O'Donoghue J, Morrison CP, Car $J$, et al. Comparison of self-administered survey questionnaire responses collected using mobile apps versus other methods. Cochrane Database Syst Rev. 2015;7:MR000042. https://doi.org/10.1002/14651858.MR000042.pub2.

17. Blumenberg C, Barros AJD. Response rate differences between web and alternative data collection methods for public health research: a systematic review of the literature. Int J Public Health. 2018;63(6):765-73. https://doi. org/10.1007/s00038-018-1108-4

18. Hartmann RC, Rossetti BR, Siqueira Pinheiro L, Poli de Figueiredo JA, RossiFedele G, S. Gomes M, et al. Dentists' knowledge of dental trauma based on the International Association of Dental Traumatology guidelines: a survey in South Brazil. Dent Traumatol. 2019;35(1):27-32. https://doi.org/10.1111/ edt.12450.

19. Sarkis-Onofre R, Pereira-Cenci T, Opdam NJ, Demarco FF. Preference for using posts to restore endodontically treated teeth: findings from a survey with dentists. Braz Oral Res. 2015;29:1-6. https://doi.org/10.1590/1807-31 07bor-2015.vol29.0001.

20. Demarco FF, Baldissera RA, Madruga FC, et al. Anterior composite restorations in clinical practice: findings from a survey with general dental practitioners. J Appl Oral Sci. 2013;21(6):497-504. https://doi.org/10.1590/1 679-775720130013.

21. Gullberg J, Lindh C, Axtelius B, Horner K, Devlin H, Povlsen L. Osteoporosis risk assessment in primary dental care - the attitudes of Swedish dentists, patients and medical specialists. Gerodontology. 2020;37(2):208-16. https:// doi.org/10.1111/ger.12462.

22. Taguchi A, Tsuda M, Ohtsuka, et al. Use of dental panoramic radiographs in identifying younger postmenopausal women with osteoporosis. Osteoporos Int. 2006;17(3):387-94. https://doi.org/10.1007/s00198-005-2029-7.

23. Calciolari E, Donos N, Park JC, Petrie A, Mardas N. Panoramic measures for oral bone mass in detecting osteoporosis: a systematic review and metaanalysis. J Dent Res. 2015;94(3 Suppl):17S-27S. https://doi.org/10.1177/0022 034514554949.

24. Aliaga I, Vera V, Vera M, García E, Pedrera M, Pajares G. Automatic computation of mandibular indices in dental panoramic radiographs for early osteoporosis detection. Artif Intell Med. 2020;103:101816. https://doi. org/10.1016/j.artmed.2020.101816.

25. Tanaka R, Tanaka T, Yeung AWK, Taguchi A, Katsumata A, Bornstein MM. Mandibular radiomorphometric indices and tooth loss as predictors for the risk of osteoporosis using panoramic radiographs. Oral Health Prev Dent. 2020;18(1):773-82. https://doi.org/10.3290/j.ohpd.a45081.

26. Krimmel M, Ripperger J, Hairass M, Hoefert S, Kluba S, Reinert S. Does dental and oral health influence the development and course of bisphosphonaterelated osteonecrosis of the jaws (BRONJ)? Oral Maxillofac Surg. 2014;18(2): 213-8. https://doi.org/10.1007/s10006-013-0408-3.

27. Oyhanart SR, Escudero ND, Mandalunis PM. Effect of alendronate on the mandible and long bones: an experimental study in vivo. Pediatr Res. 2015; 78(6):618-25. https://doi.org/10.1038/pr.2015.163.

\section{Publisher's Note}

Springer Nature remains neutral with regard to jurisdictional claims in published maps and institutional affiliations.

Ready to submit your research? Choose BMC and benefit from:

- fast, convenient online submission

- thorough peer review by experienced researchers in your field

- rapid publication on acceptance

- support for research data, including large and complex data types

- gold Open Access which fosters wider collaboration and increased citations

- maximum visibility for your research: over $100 \mathrm{M}$ website views per year

At BMC, research is always in progress.

Learn more biomedcentral.com/submissions 